\title{
INSS Stage 1
}

National Cancer Institute

\section{Source}

National Cancer Institute. INSS Stage 1. NCI Thesaurus. Code C85417.

The tumor is confined to the original site of growth; no metastasis. 